\title{
Getting the measure of eutrophication in the Baltic Sea: towards improved assessment principles and methods
}

\author{
Jesper H. Andersen • Philip Axe • Hermanni Backer • Jacob Carstensen • \\ Ulrich Claussen • Vivi Fleming-Lehtinen • Marko Järvinen · Hermanni Kaartokallio • \\ Seppo Knuuttila • Samuli Korpinen · Aiste Kubiliute • Maria Laamanen • \\ Elzbieta Lysiak-Pastuszak • Georg Martin • Ciarán Murray • Flemming Møhlenberg • \\ Günther Nausch • Alf Norkko • Anna Villnäs
}

Received: 2 July 2009/Accepted: 2 July 2010/Published online: 21 July 2010

(C) The Author(s) 2010. This article is published with open access at Springerlink.com

\begin{abstract}
The eutrophication status of the entire Baltic Sea is classified using a multi-metric indicatorbased assessment tool. A total of 189 areas are assessed using indicators where information on reference conditions (RefCon), and acceptable deviation (AcDev) from reference condition could be combined with national monitoring data from the
\end{abstract}

J. H. Andersen $(\bowtie) \cdot$ C. Murray · F. Møhlenberg

DHI, Agern Allé 5, 2970 Hørsholm, Denmark

e-mail: jha@dhi.dk

P. Axe

SMHI, Nya Varvet 31, 42671 Västra Frölunda, Sweden

H. Backer · S. Korpinen · M. Laamanen

HELCOM, Katajanokanlaituri 6B, 00160 Helsinki,

Finland

J. Carstensen

National Environmental Research Institute (NERI),

Frederiksborgvej 399, 4000 Roskilde, Denmark

U. Claussen

Federal Environment Agency (UBA), Wörlitzer Platz 1, 06844 Dessau-Roßlau, Germany

\section{Järvinen}

Finnish Environment Institute (SYKE), Jyväskyla Office,

P.O. Box 35, 40014 Jyväskyla, Finland

V. Fleming-Lehtinen · H. Kaartokallio ·

S. Knuuttila · A. Norkko · A. Villnäs

Marine Research Centre, Finnish Environment Institute

(SYKE), P.O. Box 140, 00251 Helsinki, Finland period 2001-2006. Most areas (176) are classified as 'affected by eutrophication' and only two open water areas and 11 coastal areas are classified as 'unaffected by eutrophication'. The classification is made by application of the recently developed HELCOM Eutrophication Assessment Tool (HEAT), which is described in this paper. The use of harmonized

\author{
A. Kubiliute \\ Center of Marine Research, Taikos Av. 26, \\ 91149 Klaipeda, Lithuania \\ E. Lysiak-Pastuszak \\ IMGW, Maritime Branch, Waszyngtona 42, \\ 81-342 Gdynia, Poland \\ G. Martin \\ Estonian Marine Institute, University of Tartu, Mäealuse \\ 10a, 12618 Tallinn, Estonia \\ G. Nausch \\ Leibniz Institute for Baltic Sea Research, Seestr. 15, \\ 18119 Rostock, Germany
}
A. Norkko
Department of Marine Ecology - Kristineberg, University of Gothenburg, Kristineberg 566, 45034 Fiskebackskil, Sweden 
assessment principles and the HEAT tool allows for direct comparisons between different parts of the Baltic Sea despite variations in monitoring activities. The impaired status of 176 areas is directly related to nutrient enrichment and elevated loads from upstream catchments. Baltic Sea States have implemented nutrient management strategies since years which have reduced nutrient inputs. However, eutrophication is still a major problem for large parts of the Baltic Sea. The 2007 Baltic Sea Action Plan is projected to further reduce nutrient inputs aiming for a Baltic Sea unaffected by eutrophication by 2021 .

Keywords Eutrophication - Baltic Sea ·

Assessment · HEAT · Nutrients · Ecological status · Nutrient management strategies

\section{Introduction}

Nutrient enrichment, leading to large scale eutrophication problems in the Baltic Sea, is perhaps the single greatest threat to the Baltic Sea environment (HELCOM 2009). Nutrient enrichment results in an increase in productivity and undesirable changes in ecosystem structure and function (Ryther and Dunstan 1971; Nixon 1995; Cloern 2001). The Baltic Sea ecosystem can cope with moderate increases in eutrophication pressure, but when the limits of 'normal' ecosystem structure and function are exceeded, eutrophication becomes a problem (Ærtebjerg et al. 2003; Rönnberg and Bonsdorff 2004; Feistel et al. 2008; HELCOM 2009).

The 2007 Baltic Sea Action Plan (BSAP), prepared under the Convention for the Protection of the Baltic Sea Environment, identifies eutrophication as one of the four main issues to address in order to improve the environmental health of the Baltic Sea (HELCOM 2007a). The BSAP sets a strategic goal related to eutrophication: 'a Baltic Sea unaffected by eutrophication'. This is linked to a set of Ecological Objectives, which correspond to good ecological/ environmental status sensu the European Water Framework Directive (WFD) and Marine Strategy Framework Directive (MSFD) (Anon. 2000, 2008a, b). The ecological objectives associated with eutrophication are: (i) concentrations of nutrients close to natural levels, (ii) natural levels of algal blooms, (iii) clear water, (iv) natural distribution and occurrence of plants and animals, and (v) natural oxygen levels.
In the BSAP, the Baltic Sea states acknowledge that a harmonized approach to assessing the eutrophication status of the Baltic Sea is required. Therefore, the Baltic Sea states performed a Baltic Sea-wide thematic assessment of eutrophication status including development of a tool for integrated assessment, the HELCOM Eutrophication Assessment Tool (HEAT). Hence, this article describes the principles and methods of the HEAT tool.

HEAT builds on the OSPAR Common Procedure developed for assessment and identification of 'eutrophication problem areas' in the OSPAR convention area, in particular the North Sea, the Channel, the Skagerrak and the Kattegat (see OSPAR 2003, 2008). It also makes use of some of the key assessment principles of the WFD, e.g. the calculation of an Ecological Quality Ratio (EQR) and the 'one out, all out' principle (Anon. 2000; Borja et al. 2009). HEAT arrives at a primary classification of 'areas affected by eutrophication'. In addition, HEAT results in a secondary assessment of the confidence of the primary assessment, a feature missing in other eutrophication assessment tools (Andersen et al. 2010). This study presents the principles and mechanics of the assessment tool and its results when applied to the Baltic Sea.

\section{Methodology}

Study area

The Baltic Sea is an inland sea with a surface area of $415,200 \mathrm{~km}^{2}$ and is one of the largest brackish-water basins in the world. It is commonly divided into several sub-basins separated by sills, including a transition zone to the North Sea consisting of the Kattegat and the Belt Sea (\#11-17 in Fig. 1). These sub-areas differ considerably in several physical characteristics including ice cover, temperature, salinity, and residence time of the water (Leppäranta and Myrberg 2009). Surface salinity provides an illustrative example: while it is normally $20-25$ in the Kattegat area, it is only 6-8 in the central Baltic Sea and drops below 2 in the northern and eastern extremities of the Bothnian Bay and the Gulf of Finland. As a result the composition of the biota changes considerably along these gradients (HELCOM 2007b; Feistel et al. 2008).

The human population in the catchment is 85 million, and human activities display a similar, 
Fig. 1 The Baltic Sea with location of 'assessment units' in coastal waters (172 units marked with open circles) and open basins (17 units shown with numbered circles). Numbers refer to Table 1. Reproduced with permission from HELCOM

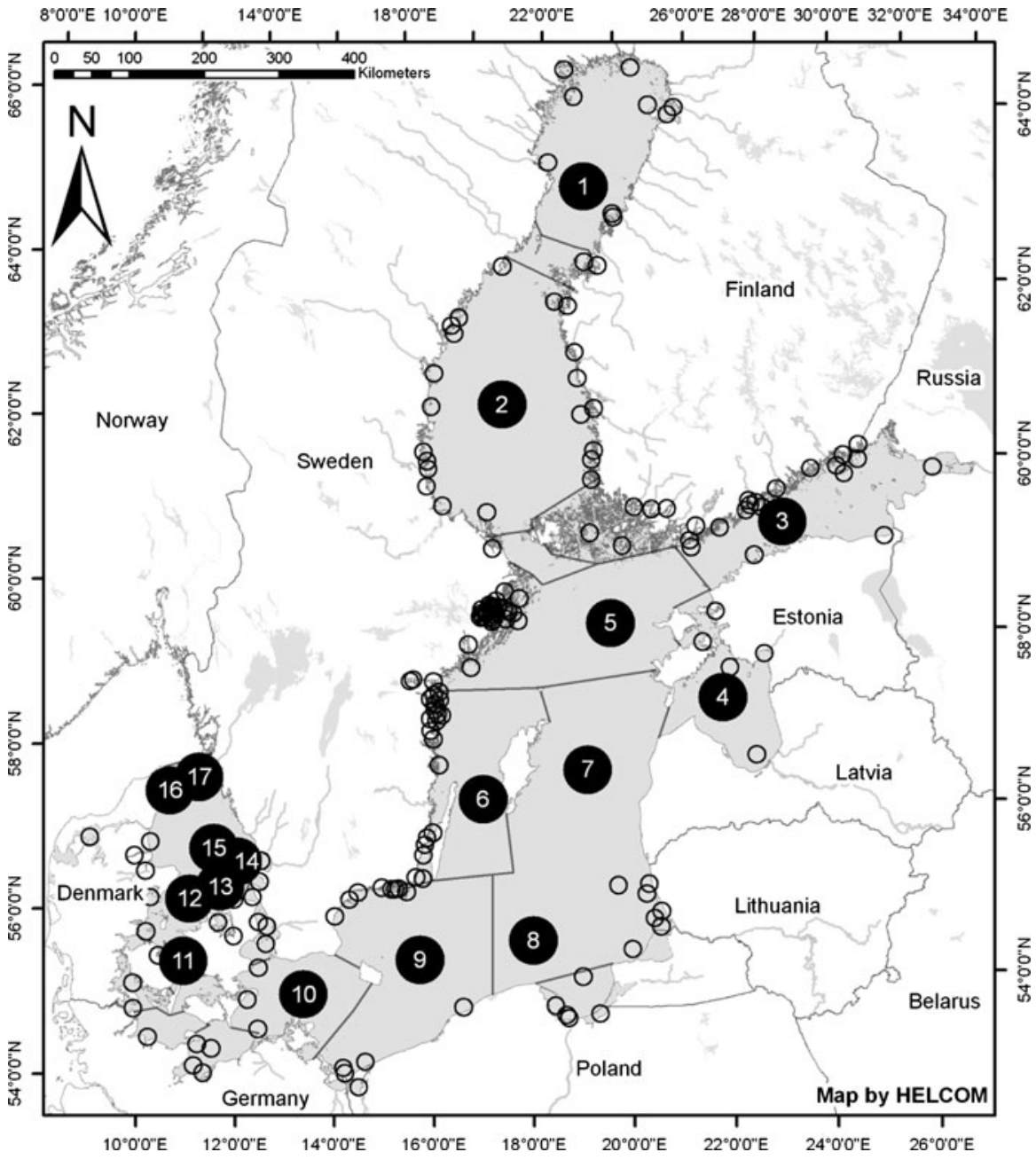

distinctive north-south, east-west pattern. Population density outside main cities varies from more than 100 persons per $\mathrm{km}^{2}$ in the southern and south-western parts to less than 1 person per $\mathrm{km}^{2}$ in the northern and north-eastern parts of the catchment area (CIESN \& CIAT 2005). In terms of land use there is a high proportion of agricultural land in the south-eastern and south-western parts, while boreal forest, wetlands and barren areas dominate in the north (Anon. 2001).

The long residence times (Leppäranta and Myrberg 2009) and the strong saline stratification of the water column, including natural hypoxia in the deep basins (Conley et al. 2009a), make large parts of the Baltic Sea sensitive to nutrient enrichment and eutrophication. Human activities and settlement, including e.g. agriculture, urban and industrial waste water, energy production and transport result in greatly increased loads of nutrients (nitrogen and phosphorus) from the (relatively large) $1,700,000 \mathrm{~km}^{2}$ catchment area entering the Baltic Sea (HELCOM 2004; Schernewski and Neumann 2005; Savchuk et al. 2008; HELCOM 2009).

\section{Data sources}

Three types of data are used in this study: (1) monitoring data for 2001-2006 (in some cases only 2001-2005 or 2001-2004), (2) information on reference conditions (RefCon), and (3) 'target levels' defined as acceptable deviation (AcDev) from RefCon. 
Most of the monitoring data representing actual status (AcStat) originate from the HELCOM Cooperative Monitoring in the Baltic Marine Environment Programme (HELCOM COMBINE, see HELCOM (2008) for details and note that the Kattegat is included under both HELCOM and OSPAR) carried out in cooperation between the Baltic countries, and partly from national monitoring and assessment activities (e.g. Svendsen et al. 2005; OSPAR 2008).

Data representing long-term trends in inputs of nutrients (nitrogen and phosphorus) to the Baltic Sea are derived from the HELCOM Fifth Pollution Load Compilation (HELCOM 2010). All measurements and analytical methods used as well as quality assurance procedures are described in details in the HELCOM COMBINE Manual, Parts A, B and C (HELCOM 2008).

In this study, specific focus has been placed on indicators relevant to HELCOM objectives (HELCOM 2007b; Backer and Leppänen 2008), in particular nutrients (objective i), chlorophyll-a (objective ii), water transparency (objective iii), benthic invertebrates and submerged aquatic vegetation (SAV) (objective iv). For the description of the AcStat all Baltic Sea states have used the 2001-2006 period, except Denmark, which used the period 2001-2005 for the Kattegat and Great Belt and 2001-2004 for all other areas.

\section{RefCon}

RefCon, which are “... a description of the biological quality elements that exist, or would exist, at high status, that is, with no, or very minor disturbance from human activities" (Anon. 2000) are used to quantify the degree of disturbance observed in the environment. Furthermore, they should represent part of nature's continuum and must reflect variability. Three principles for making the concept of RefCon operational are (1) reference sites, (2) historical data, and (3) modelling. Expert judgement can be used as a supplement when spatially based (option 1 and 2), modelled (option 3 ) or combinations of 1, 2 and 3 are not possible. In this study, the RefCon are mostly based on historical data and modelling, since reference sites no longer exist in the Baltic Sea and the use of expert judgement is occasionally less transparent. The RefCon's for nutrients (dissolved inorganic nitrogen (DIN) and dissolved inorganic phosphorus
Fig. 2 Reference conditions (RefCon) for open areas of the Baltic Sea. Numbers refer to Fig. 1. For DIN and DIP grey bars are winter mean RefCon's and black bars are winter maximum RefCon's. Please note that no data on DIP are available for area \#4, no data on Secchi depth are available for areas \#12, 13, and 16 and no data on benthic invertebrates are available for areas \#4, 6, and 11-17

(DIP)), chlorophyll-a, water transparency (Secchi depth) and benthic invertebrates in the open parts of the Baltic Sea, obtained from various sources described below, are shown in Fig. 2.

For nutrients, chlorophyll-a and water transparency, RefCon's are basin specific and mostly based on historical data (HELCOM 2006; Fleming-Lehtinen 2007; Fleming-Lehtinen et al. 2008; Henriksen 2009). Modelled and site-specific RefCon's have been used for parts of the Danish Straits (OSPAR 2008). The reference values used are largely in line with those presented by other sources, e.g. Sanden and Håkansson (1996), Aarup (2002) and Schernewski and Neumann (2005).

RefCon's for benthic invertebrate diversity in open water basins, measured as gamma diversity, i.e. the average number of species in a sub-basin per year, were calculated based upon data from 1965 to 2006 (HELCOM 2009). RefCon's varied by an order of magnitude between the Arkona Basin and the Bothnian Bay due to the salinity gradient, which constrains species distributions (Bonsdorff and Pearsson 1999). For the coastal water assessments, different national indices have been used; see HELCOM (2009) for details.

For SAV in coastal waters, namely depth distribution of Fucus vesiculosus and Zostera marina, which constitute monitoring species in coastal waters only, RefCon's are based on historical records, e.g. Reinke (1889), Waern (1952) and von Wachenfeldt (1975) as well as Boström et al. (2003), Martin (1999), and Krause-Jensen et al. (2003).

\section{AcDev}

For the open basins of the Baltic Sea, AcDev values are set basin-wise for each indicator. Two different principles are used for setting the AcDev, according to whether indicators show a positive response (increasing in value) to increases in nutrient inputs or a negative response (decreasing in value). For an indicator showing positive response (e.g. nutrient concentrations and chlorophyll-a), AcDev has an 

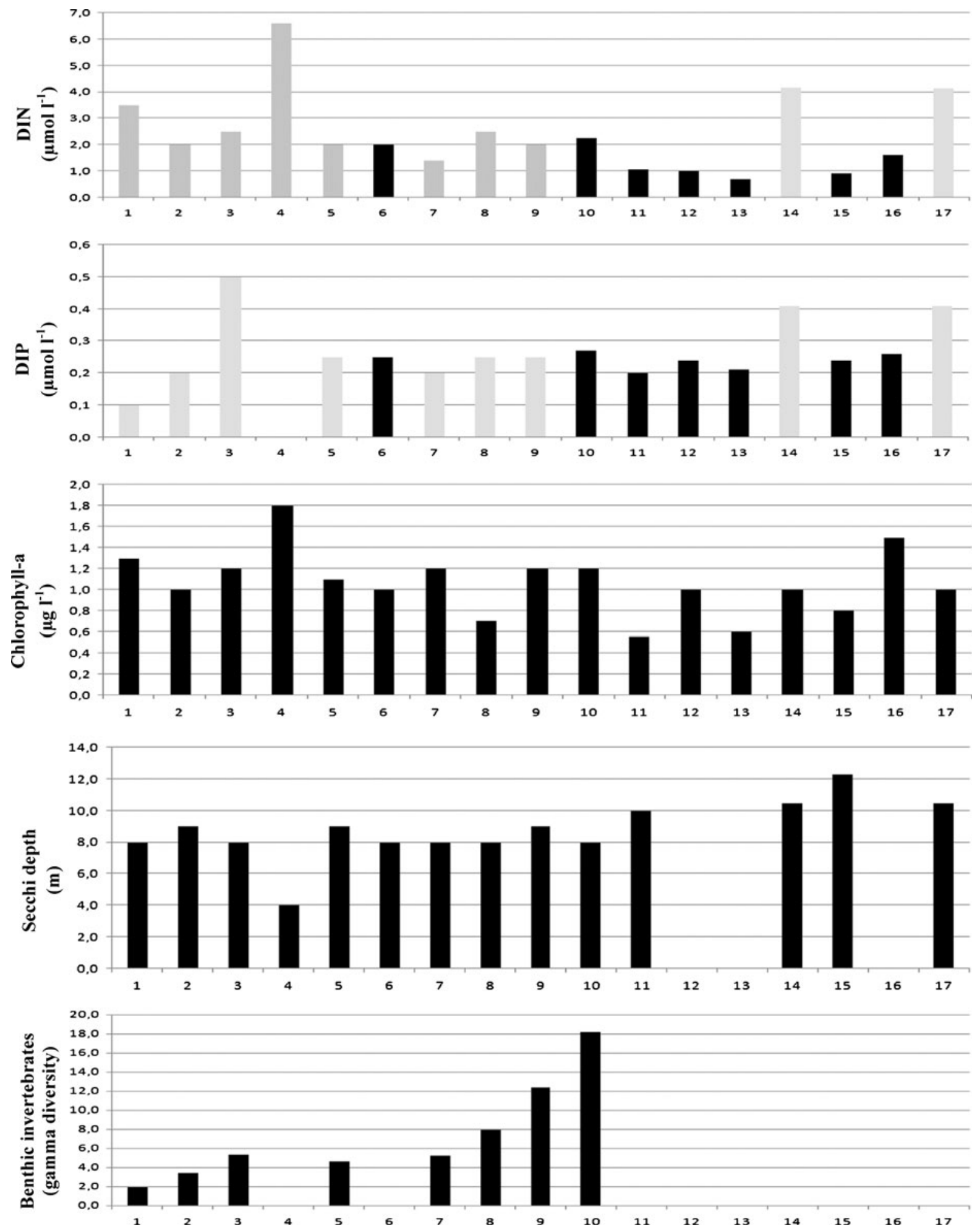
upper limit of $+50 \%$ deviation from RefCon (HELCOM 2009). Setting AcDev to 50\% implies that low levels of disturbance (defined as less than $+50 \%$ deviation) resulting from human activity are considered acceptable while moderate (i.e. greater than $+50 \%$ ) deviations are not considered acceptable for the body of water in question. However, in exceptional cases the $+50 \%$ AcDev can be exceeded if scientifically justified. For indicators responding negatively to increases in nutrient input (e.g. Secchi depth and depth limit of SAV) the AcDev's have in principle a limit of $-25 \%$ (HELCOM 2009), although AcDev's used for benthic invertebrates are slightly greater in magnitude, ranging from -27 to $-40 \%$ (HELCOM 2009). Whereas an indicator with positive response can theoretically show unlimited deviation, indicators showing negative response have a maximum deviation of $-100 \%$ and a deviation of $-25 \%$ is, in most cases, interpreted as the boundary between low and moderate levels of disturbance. These $+50 \%$ and $-25 \%$ "principles" are under discussion, but these initial and pragmatic values are in accordance with the WFD (Anon. 2000, 2005) and other eutrophication assessment approaches (Bricker et al. 2003; HELCOM 2006; NOAA 2007; OSPAR 2008; Bricker et al. 2008; Claussen et al. 2009). The AcDev's used for the coastal waters are largely defined by the WFD implementation process, in particular the WFD intercalibration activity in the Baltic Sea (Anon. 2008b).

Assessment principles and methods

The methodology used in this study to assess eutrophication status of a water body, the HEAT, is based on indicators, grouped according to a predefined manner. The grouping method used follows the WFD (Anon. 2000, 2005) quality elements (physicalchemical features, phytoplankton, SAV, benthic invertebrates) corresponding to HELCOM eutrophication objectives i, ii, iii (physical-chemical features), iv (phytoplankton) and $\mathrm{v}$ (SAV \& benthic invertebrates); subsequently combined into a final classification of 'eutrophication status'.

Using the described RefCon, AcDev and AcStat concepts, the basic assessment principle becomes: RefCon \pm AcDev $=$ EutroQO, where the latter is a "eutrophication quality objective" (or target) corresponding to the boundary between good and moderate ecological status. When the AcStat data exceed the EutroQO or target, the areas in question is regarded as "affected by eutrophication" cf. the BSAP.

Thus, following the basis assessment principle described above, a selection of indicators with RefCon and AcDev values turns qualitative goals like HELCOM's five eutrophication objectives into operational targets, on which objective and transparent assessments of eutrophication status can be based. While the RefCon's can be considered the "anchors" of the assessment, AcDev's from RefCon's are the necessary "yardsticks" while AcStat is actual indicator status. The assessment principles used by HEAT are summarised in Fig. 3.

The HEAT tool integrates all the elements described above and is based on: (1) Indicators representing well documented eutrophication effects with synoptic information on RefCon, AcDevs, and AcStat, (2) Quality Elements sensu the WFD, (3)

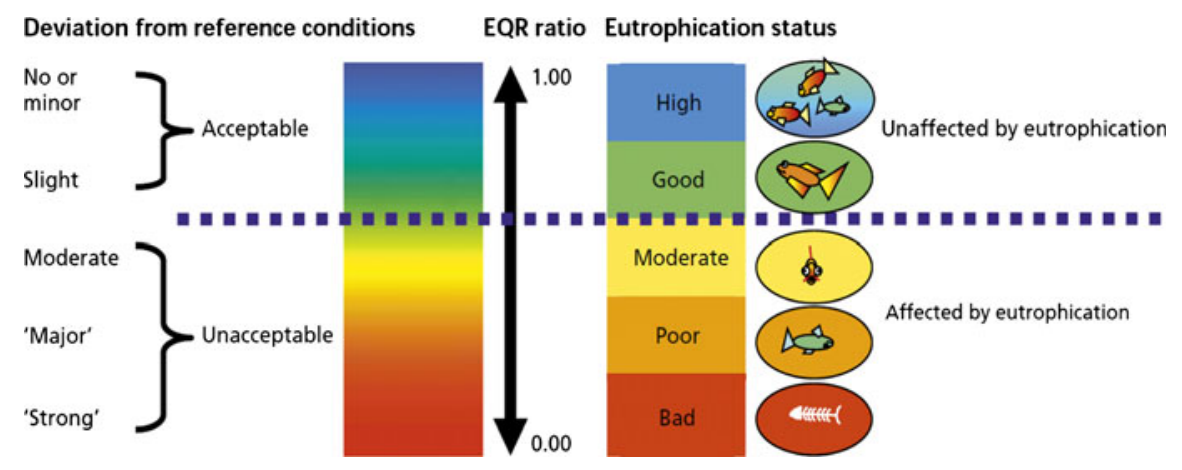

Fig. 3 Illustration of the key assessment principles used in the HEAT tool. Please note that HEAT combines the principles of the HELCOM Baltic Sea Action Plan (right side of the figure

representing open waters) with principles from the EU Water Framework Directive (left side of the figure representing coastal waters). Fish by courtesy of Peter Pollard, Scottish EPA 
HELCOM Ecological Objectives, (4) weighting of indicators within quality elements, and (5) integration of the Quality Elements used into a final assessment based on the 'One out-all out' principle sensu the WFD.

\section{Step 1: Indicators and boundary setting}

The EQR is a dimensionless measure of the observed value (AcStat) of an indicator compared with the reference value (RefCon). The ratio is equal to 1.00 if AcStat is better than or equal to RefCon and approaches 0.00 as deviation from RefCon becomes large.

Step 1A: Indicators with a positive numerical relationship to nutrient input For an indicator showing positive response to nutrient input, the EQR is defined by:

$\mathrm{EQR}=$ RefCon $/$ AcStat

$0 \leq \mathrm{EQR} \leq 1$

where the observed value of the indicator (AcStat) is equal to or less than the reference value, then the $\mathrm{EQR}$ is equal to the maximum achievable, 1.00. For a given reference value, increasing values of AcStat give lower $\mathrm{EQR}$, with $\mathrm{EQR}$ approaching zero as the status value becomes infinitely large (Fig. 4a).

The value of EQR is used to assign a quality class to the observed status. The classes in descending order of quality are RefCon, High, Good, Moderate, Poor, Bad. The central definition of the quality classes is given by the value of AcDev. The boundary between Good and Moderate status is defined as being where the deviation from RefCon is equal to the AcDev. That is:

AcStat $=(1+$ AcDev $) \times$ RefCon

Substituting for AcStat in (1) gives:

$$
\mathrm{EQR}_{\mathrm{Good} / \text { Moderate }}=1 /(1+\mathrm{AcDev})
$$

The EQR boundary between High and Reference status is always set equal to 0.95 . If $\mathrm{EQR}$ is above 0.95 , it is implicitly assumed that the indicator has a status equal to RefCon. This deviation is allowed in order to take into account a degree of uncertainty in the observations of RefCon and present status as well. Thus, this permissible deviation from RefCon (5\%) represents a generic estimate of the uncertainty margin for all indicators. The quality class of "Reference" will rarely be used and quality class "High" therefore, in practice, represents the highest

\section{A}

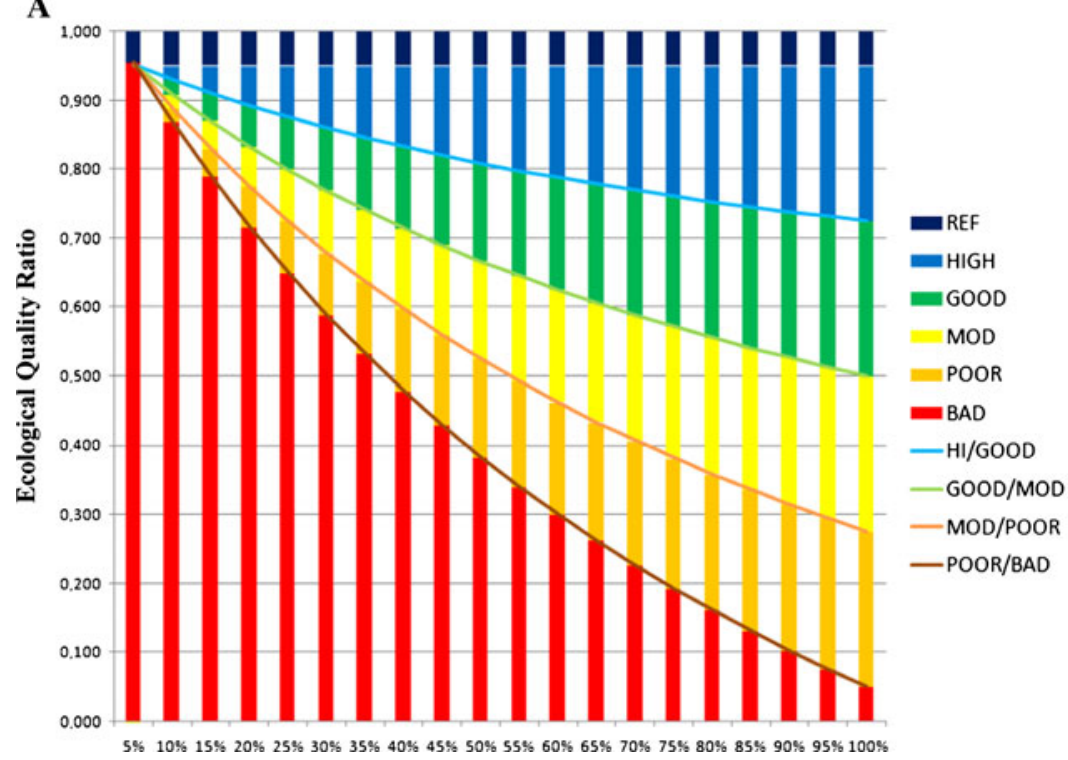

B

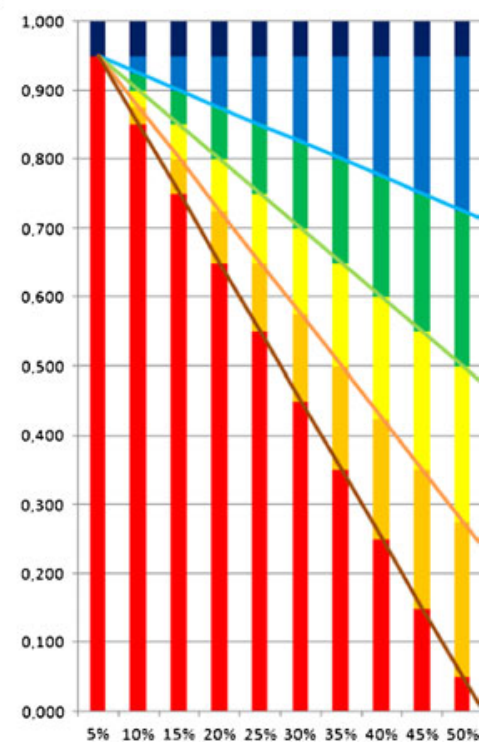

Fig. 4 Illustration of the boundary (target) setting, when the indicator responds numerically positive to nutrient loads and enrichment (a) and when the indicator responds numerically negative (b) 
achievable status. However, the High/Ref boundary is employed in determining boundaries between the other classes.

The values for the boundary between Reference/ High status and the boundary between Good/Moderate status constitute fixed points from which the remaining boundary values are calculated. For practical reasons the span of the two highest classes and the next two classes have equal width, i.e.:

$$
\begin{aligned}
& \mathrm{EQR}_{\text {RefCon/High }}-\mathrm{EQR}_{\mathrm{Good} / \text { Moderate }} \\
& \quad=\mathrm{EQR}_{\text {Good/Moderate }}-\mathrm{EQR}_{\text {Poor/Bad }}
\end{aligned}
$$

That is, the difference between the values of EQR defining the Reference/High and Good/Moderate boundaries is equal to the difference between the Good/Moderate and Poor/Bad boundary values. This Eq. 10 can be rearranged to give the value for the boundary between Poor and Bad status:

$$
\mathrm{EQR}_{\text {Poor } / \mathrm{Bad}}=2 \mathrm{EQR}_{\mathrm{Good} / \text { Moderate }}-\mathrm{EQR}_{\mathrm{RefCon} / \mathrm{High}}
$$

For example, consider a case where the AcDev from RefCon is $50 \%$. The boundary between Good and Moderate status is $1 /(1+0.5)=0.667$. And according to (6), the boundary between Poor and Bad status lies at 0.383 (Fig. 3a).

This leaves two remaining boundaries to be defined, the boundary between Good and High status and the boundary between Poor and Moderate Status. These boundaries are defined as the midpoints between the two adjacent boundaries:

$$
\begin{aligned}
\mathrm{EQR}_{\mathrm{High} / \mathrm{Good}}= & 0.5 \mathrm{EQR}_{\text {RefCon } / \text { High }} \\
+ & 0.5 \mathrm{EQR}_{\text {Good } / \text { Moderate }} \\
\mathrm{EQR}_{\text {Moderate } / \text { Poor }}= & 0.5 \mathrm{EQR}_{\text {Good } / \text { Moderate }} \\
& +0.5 \mathrm{EQR}_{\text {Poor } / \text { Bad }}
\end{aligned}
$$

For the example of AcDev equal to 50\% the values for the High/Good and Moderate/Poor boundaries equal 0.808 and 0.525 , respectively. Figure 3 a shows how the value of EQR for the boundary between the classes varies with the AcDev from RefCon.

The method used for calculating class boundaries does not allow for use of AcDev greater than $110 \%$ for indicators with a positive response to nutrient input, as the Poor/Bad boundary would otherwise become negative (Fig. 3a). Consequently, it would therefore become impossible to obtain a "Bad" status as an EQR cannot be negative, irrespective of the extent to which the observed status exceeds RefCon.

Step 1B: Indicators with a numerical negative relationship to nutrient input For an indicator showing a negative response to nutrient input, e.g. depth limit of SAV or Secchi depth, the EQR is defined as:

$\mathrm{EQR}=$ AcStat $/$ RefCon

$0 \leq \mathrm{EQR} \leq 1$

Here, for a given reference value, the EQR is directly proportional to the observed value, and is equal to the maximum value of 1.00 if the AcStat equals or exceeds the reference value.

As for the case of positive response, the AcDev from RefCon is used to define class boundaries for classification according to EQR value. Again, the Good/Moderate boundary lies where the deviation from RefCon is equal to the AcDev (3).

Using (3) to substitute for AcStat in (9), and remembering that $\mathrm{AcDev}$ is negative, gives:

$\mathrm{EQR}_{\text {Good/Moderate }}=(1-\mathrm{AcDev})$

For an AcDev of $50 \%$, the boundary for Good/ Moderate status is 0.5 . Figure $4 \mathrm{~b}$ shows how the class boundaries vary with the AcDev. Given the value for the Good/Moderate boundary and the Ref/High boundary (0.95), the values for the remaining boundaries are calculated in the same manner as described above for indicators with a positive response to nutrient input. Figure $4 \mathrm{~b}$ is useful in illustrating the limit on allowable AcDev for an indicator with negative response. Choosing an AcDev greater than $52.5 \%$ would mean that according to the previously described method of calculating class boundaries, the Bad/Poor boundary becomes negative (Fig. 4b) and it is therefore impossible to arrive at a classification of Bad, no matter how far from RefCon the observed status is.

\section{Step 2: Quality elements and final classification}

An EQR value and a set of class boundaries are calculated for each indicator, but the overall status classification depends on a combination of indicators. First, indicator EQR values are combined to give an EQR value for a specific Quality Element (QE), and 
A DIN in surface waters

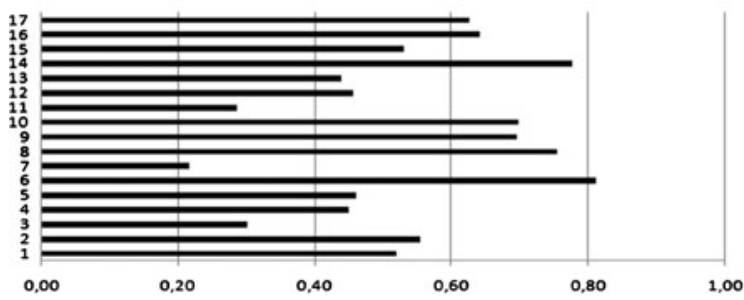

B DIP in surface waters

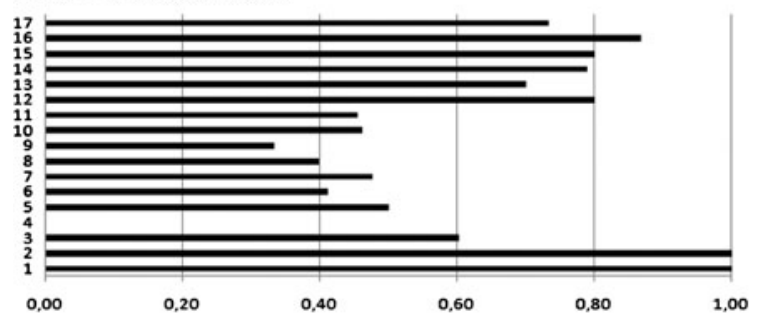

C Chlorophyll-a in surface water

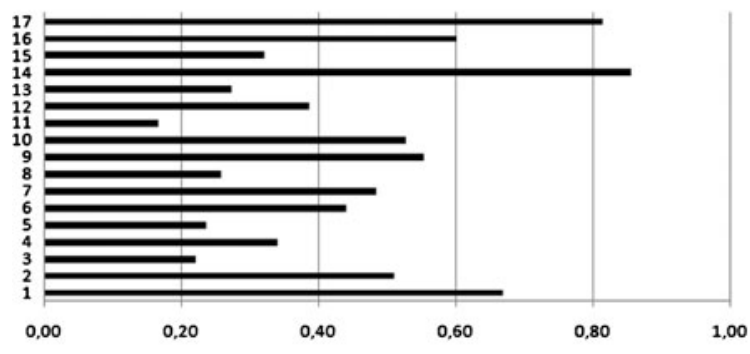

D Secchi depth

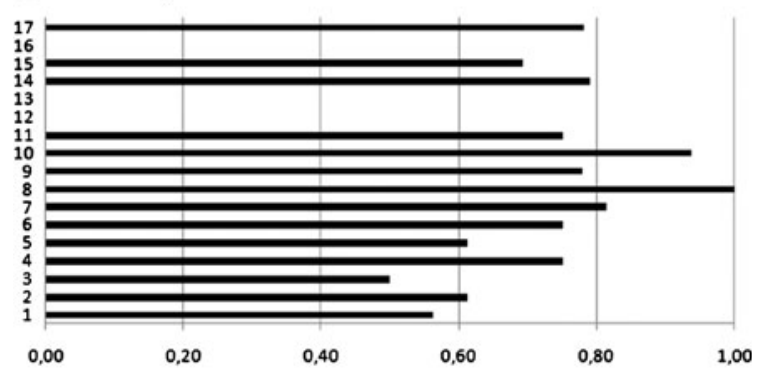

E Benthic invertebrates

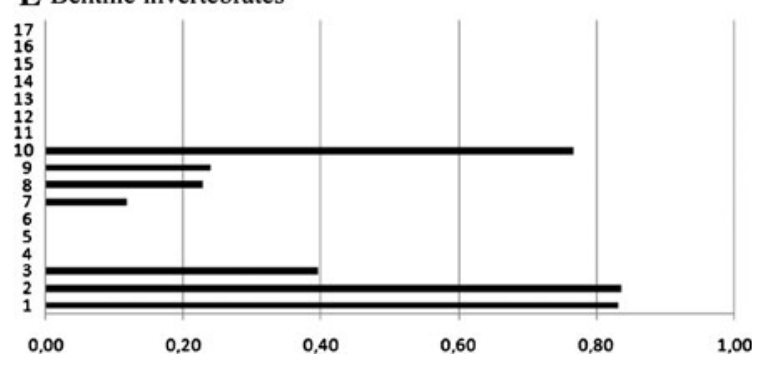

similarly the indicator class boundaries are combined to give the class boundaries for the $\mathrm{QE}$. In the simplest case, where all indicators within a QE have
4 Fig. 5 Ecological Quality Ratios (EQRs) calculated for open water bodies for a Dissolved Inorganic Nitrogen (DIN), b Dissolved Inorganic Phosphorus (DIP), c Chlorophyll-a, d Water transparency (as Secchi depth), and e gamma diversity for benthic invertebrates. Numbers refer to Fig. 1. Please note that no data on DIP are available for area \#4, no data on Secchi depth are available for areas \#12,13, and 16 and no data on benthic invertebrates are available for areas \#4, 6, and 11-17

equal weights, the EQR for the $\mathrm{QE}$ is the average of the indicators' EQRs within the QE and each QE class boundary (e.g. Moderate/Good boundary) is found as the average of the class boundary values for all indicators representing that specific QE.

Within a QE, it is also possible to assign weighting factors to indicators according to expert judgement. The classification of the $\mathrm{QE}$ is then given by comparison of the weighted averages of the EQRs with the weighted averages of the individual class boundaries. Thus, the same weighting is applied both in calculation of the EQR for the specific QE as well as $\mathrm{QE}$ class boundary values.

The lowest rated of the QEs will because of the 'One out-all out' principle determine to final status classification. This principle is employed for two reasons: (1) all five HELCOM objectives for the open basins are required to be met independently, and (2) this principle is stated in the WFD (Anon. 2000) for assessing ecological status of coastal waters.

\section{Results}

Eutrophication status in the Baltic Sea has been calculated for 189 assessment units: 172 coastal areas and 17 open water bodies. In the open water areas, monitoring data was combined into larger areas by calculation of mean values to give a common status for an entire sub-basin, whereas the coastal areas were assessed in smaller scale (Fig. 1). The EQR values for nutrients, chlorophyll-a, water transparency and the gamma diversity of benthic invertebrates are presented in Fig. 5.

For the open water bodies, 15 out of 17 are classified as 'areas affected by eutrophication'. The results are summarised in Table 1. Only the Bothnian Bay and the north-eastern part of the Kattegat are regarded as 'unaffected by eutrophication'. The results of the open water body classifications for nutrients, chlorophyll-a, water transparency, and 
Table 1 Classification of eutrophication status for 17 open water areas in the Baltic Sea region

\begin{tabular}{|c|c|c|c|c|c|}
\hline \multirow[t]{2}{*}{ No. } & \multirow[t]{2}{*}{ Area } & \multicolumn{3}{|c|}{ Ecological quality ratio } & \multirow[t]{2}{*}{ Eutrophication status } \\
\hline & & $\mathrm{PC}$ & $\mathrm{PP}$ & $\mathrm{BIC}$ & \\
\hline 1 & Bothnian Bay & $0.729(\mathrm{H})$ & $0.668(\mathrm{H})$ & $0.830(\mathbf{G})$ & Good \\
\hline 2 & Bothnian Sea & $0.724(\mathrm{G})$ & $0.508(P)$ & $0.834(\mathrm{H})$ & Poor \\
\hline 3 & Gulf of Finland & $0.468(\mathrm{P})$ & $0.220(\mathrm{~B})$ & 0.394 (B) & $\mathrm{Bad}$ \\
\hline 4 & Gulf of Riga & $0.543(\mathrm{M})$ & $0.340(B)$ & - & Bad \\
\hline 5 & Northern Baltic Proper & $0.523(\mathrm{P})$ & $0.231(\mathrm{~B})$ & $0.000(B)$ & Bad \\
\hline 6 & Western Gotland Basin & $0.660(\mathrm{M})$ & $0.432(P)$ & - & Poor \\
\hline 7 & Eastern Gotland Basin & $0.610(\mathrm{M})$ & $0.486(\mathrm{P})$ & 0.116 (B) & $\mathrm{Bad}$ \\
\hline 8 & SE Gotland Basin, open parts & $0.745(\mathrm{G})$ & $0.400(\mathrm{P})$ & 0.222 (B) & Bad \\
\hline 9 & Bornholm Basin & $0.602(\mathrm{M})$ & $0.553(\mathrm{M})$ & 0.239 (B) & Bad \\
\hline 10 & Arkona Basin & $0.616(M)$ & $0.535(\mathrm{M})$ & $0.764(\mathrm{G})$ & Moderate \\
\hline 11 & Great Belt & 0.356 (B) & 0.295 (B) & - & $\mathrm{Bad}$ \\
\hline 12 & Kattegat, south-western & $0.716(\mathrm{H})$ & $0.460(\mathrm{P})$ & $0.584(B)$ & $\mathrm{Bad}$ \\
\hline 13 & Kattegat, south open parts & $0.561(\mathrm{M})$ & 0.351 (B) & - & $\mathrm{Bad}$ \\
\hline 14 & Kattegat, south-eastern & $0.821(\mathrm{G})$ & $0.588(\mathrm{M})$ & - & Moderate \\
\hline 15 & Kattegat, central & $0.691(\mathrm{M})$ & $0.440(P)$ & $0.549(\mathrm{M})$ & Poor \\
\hline 16 & Kattegat, north-eastern & $0.787(\mathbf{G})$ & $0.813(\mathrm{H})$ & - & Good \\
\hline 17 & Kattegat, north-western & $0.845(\mathrm{H})$ & $0.603(M)$ & - & Moderate \\
\hline
\end{tabular}

The eutrophication status is based on the 'One out-all out' principle. See Fig. 1 for location of the areas. Detailed HEAT calculations are available as Electronic Supplementary Material in Andersen et al. (2010). Please note that all values are EQR values Please note that the EQR values in bold are decisive for the final classification of eutrophication status

$P C$ physical-chemical indicators, $P P$ phytoplankton, and $B I C$ benthic invertebrate communities, $H$ High, $G$ Good, $M$ Moderate, $P$ Poor, $B$ Bad

benthic invertebrates are presented in the following sections. The detailed HEAT classifications for are available as electronic supplementary material in Andersen et al. (2010).

\section{Nutrients}

The highest DIN concentrations are found in the Bothnian Bay, which is predominantly P-limited (Tamminen and Andersen 2007) and therefore DIN may accumulate to reach levels above those in other basins (for actual data, see electronically supplementary material in Andersen et al. 2010). DIN concentrations in the Gulf of Finland are also high due to large fluvial input of nutrients mainly from the Neva River. For the other basins, DIN winter means vary between 3 and $4 \mu \mathrm{mol} 1^{-1}$. The Gulf of Riga and the Gulf of Finland have the highest TN annual means (26 and $24 \mu \mathrm{mol} 1^{-1}$, respectively), which are due to large riverine discharges to both basins (Fig. 5a). The other basins have TN levels between 18 and
$21 \mu \mathrm{mol} \mathrm{l}^{-1}$, with the lowest concentrations in the Danish Straits. From the Baltic Proper to the Danish Straits, there is a natural decreasing spatial gradient owing to the mixing with Skagerrak surface water that generally has lower TN levels.

High DIP winter means are found in the Gulf of Riga and the Gulf of Finland $\left(0.78\right.$ and $0.84 \mu \mathrm{mol} \mathrm{l}^{-1}$, respectively) owing to the large influence from riverine discharges and the upwelling of bottom waters rich in phosphorus deriving from the Baltic Proper (Pitkänen et al. 2001). DIP levels in the Bothnian Sea, the Baltic Proper and the Danish Straits are similar $\left(0.35-0.47 \mu \mathrm{mol} \mathrm{l}^{-1}\right)$, whereas DIP concentrations in the Bothnian Bay are very low $\left(0.06 \mu \mathrm{mol}^{-1}\right)$. These spatial differences are unaltered for $\mathrm{TP}$, with high levels in the Gulf of Riga and the Gulf of Finland (0.70 and $0.85 \mu \mathrm{mol} 1^{-1}$, respectively), moderate TP levels in the Baltic Proper and the Danish Straits $\left(\sim 0.58 \mu \mathrm{mol} \mathrm{l}^{-1}\right)$ with slightly lower levels in the

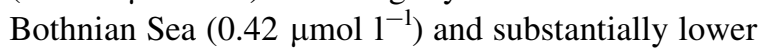
in the Bothnian Bay $\left(0.16 \mu \mathrm{mol}^{-1}\right)$. 
The EQR values for DIN vary between 0.22 and 0.81 (see Fig. 5a). For DIP, EQR values vary between 0.33 and 1.00, the latter being an indication of almost pristine conditions in the Bothnian Bay and the Bothnian Sea (Fig. 5b). As expected, nutrient status is acceptable in the Bothnian Bay (area 1). The only other areas where nutrient status is acceptable are the northern parts of the Kattegat (areas 16 and 17), areas 2 (Bothnian Sea), 8 (south-eastern Baltic Proper), and 14 (south-eastern Kattegat).

Phytoplankton and water transparency

Mean summer (June-September) chlorophyll-a concentrations are highest for the open water bodies in the Gulf of Finland, the Northern Baltic Proper and the Gulf of Riga (5.4, 4.8 and $5.3 \mu \mathrm{g}^{-1}$, respectively). In other open water bodies, average chlorophyll-a concentrations range from 1.9 to $2.7 \mu \mathrm{g} \mathrm{l}^{-1}$. The variability in summer (June-September) chlorophyll-a observations in 2001-2006 is high, with individual values ranging from 0.1 to $>50 \mu \mathrm{g} \mathrm{l}^{-1}$.

In most of the open Baltic Sea areas, chlorophyll-a concentrations indicate eutrophication. In other words, EQR values derived for chlorophyll-a show a clear deviation from RefCon (Fig. 5c). In the open sea, the chlorophyll-a derived status is the highest in the Bothnian Bay and the Kattegat (0.67 and 0.63, respectively) and lowest in the Gulf of Finland, the Northern Baltic Proper, and the Gulf of Riga (0.22, 0.23 and 0.34 , respectively).

Reduced water transparency is partly an effect of increased nutrient loads, mediated through increased phytoplankton growth. In comparison to RefCon (Fig. 5d), water transparency status has decreased in all Baltic Sea sub-areas at both at coastal and open sea sites reflecting visible eutrophication effects in the entire Baltic Sea.

Water transparency status in open sea areas expressed as EQR values vary markedly in different sub-basins of the Baltic Sea. Status expressed as EQR values varies from 0.75 to 1.0 for the southern and central sub-basins, indicating a $0-25 \%$ decrease in water transparency from near-pristine RefCon. However, sub-basins north of the Northern Baltic Proper have a significantly lower status with EQR values ranging from 0.50 to 0.61 , representing a reduction of
$39-50 \%$ in water transparency compared to RefCon. The mean EQR value for all open sub-basins assessed is 0.72. In the south-eastern Gotland Basin and Arkona Basin water transparency status is highest of all open sub-basins, with EQR values of 1.0 and 0.94 respectively. In the Kattegat water transparency status exceeds the mean status (mean EQR for Kattegat sites 0.75). In the Bornholm Basin, the Western and Eastern Gotland Basin, the EQR values are nearly equal to the Kattegat (0.75-0.81). In Gulf of Riga, the two indicators used for Secchi depth have variable RefCon (4.0 $\mathrm{m}$ for the Finnish indicator and $6.0 \mathrm{~m}$ for the Latvian indicator) and result in different EQR values of 0.75 and 0.57 , respectively.

The Northern Baltic Proper and Gulf of Finland represent a distinctly lower status compared to RefCon, with EQR values of 0.61 in the open Northern Baltic Proper and 0.50 in the Gulf of Finland. In the open sea areas of the Gulf of Bothnia water transparency EQR is 0.61 in the Bothnian Sea and 0.56 in the Bothnian Bay.

\section{Benthic invertebrates}

No benthic invertebrates survive in areas with prolonged or permanent oxygen depletion such as in the deep parts of the Baltic Proper. In areas with periodic oxygen depletion every late summer and autumn, the number of benthic species is reduced significantly and mature communities cannot develop. In marine areas with temporary oxygen depletion, intermittent recovery will occur whenever conditions improve. Oxygen depletion, if rare enough, may be viewed as a temporal and spatial mosaic of disturbance that results in the loss of habitats, reductions in biodiversity, and a loss of functionally important species. Macrobenthic communities are severely degraded throughout the open sea areas of the Baltic Proper and the Gulf of Finland, whereas conditions in the Arkona Basin, the Bothnian Sea and Bothnian Bay are classified as being good (Fig. 5e).

For the open waters, the EQR values vary between 0.00 and 0.83 . The highest EQR values are as indicated above found in the Arkona Basin (0.77), the Bothnian Sea (0.83) and the Bothnian Bay (0.83). For the Baltic Proper and the Gulf of Finland, EQR values range from 0.00 to 0.39 indicating impaired environmental conditions. 
Table 2 Summary of eutrophication status classifications of 172 coastal water bodies in the Baltic Sea region

\begin{tabular}{|c|c|c|c|c|c|c|}
\hline \multirow[t]{2}{*}{ Basins and sub-basins } & \multicolumn{5}{|c|}{ Eutrophication status classification } & \multirow[t]{2}{*}{ Total } \\
\hline & High & Good & Moderate & Poor & Bad & \\
\hline Bothnian Bay & 0 & 1 & 3 & 2 & 2 & 8 \\
\hline The Quark & 0 & 1 & 1 & 0 & 0 & 2 \\
\hline Bothnian Sea & 0 & 9 & 6 & 2 & 4 & 21 \\
\hline The Archipelago and Åland Seas & 0 & 0 & 2 & 1 & 3 & 6 \\
\hline Gulf of Finland & 0 & 0 & 4 & 6 & 9 & 19 \\
\hline Gulf of Riga & 0 & 0 & 0 & 3 & 2 & 5 \\
\hline Baltic Proper, northern parts & 0 & 0 & 3 & 7 & 30 & 40 \\
\hline Eastern Gotland Basin & 0 & 0 & 0 & 0 & 7 & 7 \\
\hline Western Gotland Basin & 0 & 0 & 0 & 5 & 14 & 19 \\
\hline Gulf of Gdansk & 0 & 0 & 0 & 1 & 4 & 5 \\
\hline Bornholm Basin & 0 & 0 & 1 & 7 & 5 & 13 \\
\hline Arkona Basin & 0 & 0 & 1 & 1 & 1 & 3 \\
\hline Kiel Bight and Mecklenburg Bight & 0 & 0 & 0 & 2 & 3 & 5 \\
\hline Danish Straits including the Sound & 0 & 0 & 1 & 4 & 5 & 10 \\
\hline Kattegat & 0 & 0 & 3 & 1 & 5 & 9 \\
\hline Total & 0 & 11 & 25 & 42 & 94 & 172 \\
\hline
\end{tabular}

High and Good represent 'areas unaffected by eutrophication', while Moderate, Poor, and Bad represent 'areas affected by eutrophication'

\section{Coastal waters}

Of the 172 coastal waters assessed, 161 are classified as 'affected by eutrophication' (Table 2). Coastal waters are in general more vulnerable to nutrient inputs than open waters-important causes being the lower retention times as well as closer benthicpelagic interactions (Borum 1996; Wasmund et al. 2001). Seasonal variations in supply, removal, and transformation processes give rise to distinct seasonal patterns for nutrient concentrations in Baltic Sea coastal areas. Distinct spatial gradients are also found, with elevated nutrient concentrations in estuaries and coastal waters compared to open waters. This gradient is most pronounced in the Danish Straits and Baltic Proper. Nutrient concentrations in coastal areas of the Gulf of Finland are similar to those in the open sea because of upwelling of offshore bottom water. Detailed information on nutrient status of the coastal waters can be found in HELCOM (2009) and Lysiak-Pastuszak et al. (2009).

In a majority of coastal Baltic areas, chlorophyll-a concentrations and water transparency measurements indicate the prevalence of eutrophication (data not shown). In other words, EQR values derived from chlorophyll-a and water transparency measurements show a clear deviation from RefCon. Detailed information about the status of planktonic communities and water transparency in various coastal waters of the Baltic Sea can be found in Feistel et al. (2008) and HELCOM (2009).

Extensive seagrass meadows and perennial macroalgal communities harbour the highest biodiversity in coastal, shallow-water ecosystems. Eutrophication has complex effects on SAV causing shifting of the distribution depth limit towards the surface, preventing the settlement of new specimens on the seafloor due to increased sedimentation, and favouring opportunistic species with a short life cycle and rapid development over the perennial species, thus causing a shift in community composition. Generally, the level of eutrophication has caused serious changes in the Baltic Sea SAV communities, although in many cases the gaps in historical data do not allow us to identify the exact timing of larger shifts in communities (Torn et al. 2006). Present-day monitoring data 
show that the degradation of communities is ongoing in several areas (HELCOM 2009). At the same time, positive signs of a slowing down or reversal of some eutrophication effects on SAV parameters could be observed in areas of the Northern Baltic Proper and the Gulf of Finland, where the previous distribution of macrophyte species has recovered in some areas (Nilsson et al. 2004; HELCOM 2009).

In the western part of the Baltic Sea (the Kattegat and the Danish Straits), the EQR values for the depth distribution of Zostera marina vary between 0.89 and 0.59. With a $-25 \%$ AcDev, only the Danish coastal areas of the Kattegat have average EQR values above 0.75. For the Danish Straits, all average EQR values are below 0.75 , and hence classified as 'affected by eutrophication'. In the central, eastern and northern parts of the Baltic Sea, in areas dominated by Fucus vesiculosus, average $\mathrm{EQR}$ values vary between 0.84 and 0.55 . EQR values above 0.75 are found in the Gulf of Riga and Eastern Baltic Proper. In the Bothnian Sea, Gulf of Finland, and the western parts of the Baltic Proper, the targets for SAV are generally not met.

Macrozoobenthic communities in coastal waters are highly variable both between and within different sub-basins. In general, more sheltered and enclosed coastal water bodies are in a worse state than more exposed open coasts. Detailed information on status of benthic invertebrates in Baltic Sea coastal water can be found in HELCOM (2009).

Integrated assessment

Combining indicators and applying the 'One out-all out' principle in order to produce a final classification of eutrophication status represents a step forward from assessments based on individual indicators towards integrated assessments applying multi-metric indicator-based assessment tools such as HEAT. The results can be presented in several ways, e.g.: (1) HEAT calculations (see electronic supplementary material in Andersen et al. (2010) for details), (2) summarised as in Tables 1 and 2 as well as (3) in the form of maps of eutrophication status in the Baltic Sea.

Figure 6 presents a merger of HEAT classifications for 17 open water areas (Table 1) and 172 coastal water bodies (Table 2) into an interpolated map of eutrophication status of the Baltic Sea. All open parts of the Baltic Sea except the Bothnian Bay and the north-eastern parts of the Kattegat are classified as 'affected by eutrophication'. It should be noted that also some coastal waters situated along the Bothnian Sea are classified as 'unaffected by eutrophication'.

\section{Discussion}

This assessment of eutrophication status in the Baltic Sea compares target values (EutroQOs), derived from combining information on RefCon (representing a 'then' situation) and an AcDev with recent (2001-2006) monitoring data (representing a 'now' situation). According to the results of this study only open parts of the Bothnian Bay and north-eastern Kattegat as well as some coastal waters in Bothnian Bay are unaffected by eutrophication.

The results of this study are generally in line with previous indicator-based assessments (HELCOM 2002, 2006; Ærtebjerg et al. 2003; Rönnberg and Bonsdorff 2004) and can be directly compared with the results of national coastal assessments and the EU processes like WFD implementation in the Baltic (e.g. Anon. 2008b). An added value of the method employed here over e.g. WFD is that it uses supporting parameters, e.g. nutrients and Secchi depth, which are significantly correlated to the biological quality elements, on the same level of importance as the biological quality elements (Nielsen et al. 2002a, b; Krause-Jensen et al. 2003).

The RefCon values derived for all 17 open water 'assessment units' are based on the analysis of historical data. The RefCon values used for the open parts of the Baltic Sea represent the best available knowledge about the eutrophication status of the Baltic Sea 50-100 years ago before the onset of the current large scale eutrophication process (Schernewski and Neumann 2005; Savchuk et al. 2008) and the monitoring data used in this study represent the best available datasets for the area. Hence, these RefCon values are in principle ready for immediate use in regard to any updates of the BSAP, e.g. as done by Wulff et al. 2007 .

The principles of this assessment for setting 'target values' (e.g. the AcDev) are in line with the WFD: it is the boundary between Good Ecological Status and Moderate Ecological Status according to the WFD 
Fig. 6 Integrated and interpolated five-class classification of eutrophication status in the Baltic Sea region. The interpolation was made by inverse distance weighting method and the gradients among the point values were permitted to change over intermediate distances. While the status of offshore areas was pooled to a single value from multiple point values, the coastal assessment units were treated as separate and were given a $25 \mathrm{~km}$ effect radius. Reproduced with permission from HELCOM

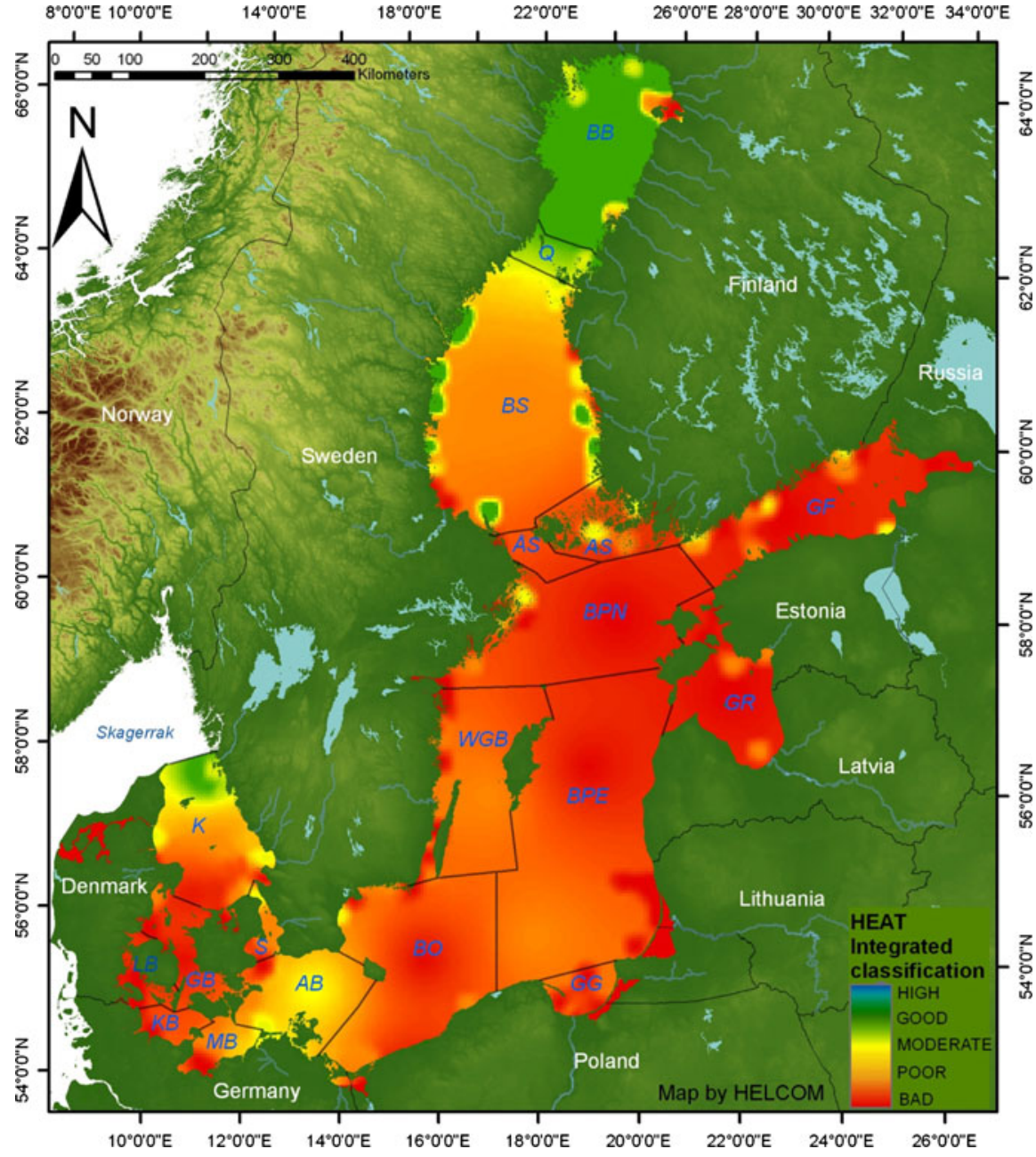

(Anon. 2000). For Good Ecological Status, which together with High Ecological Status, is considered acceptable status, the values of the biological quality elements show low levels of disturbance from RefCon as a result of human activity. For Moderate Ecological Status, which together with Poor and Bad Ecological Status, is considered an unacceptable status, the values of the biological quality elements, compared to RefCon, deviate moderately (or more) from those normally associated with the water body type under undisturbed conditions.

The nutrient concentrations overall reflect the balance between inputs from land, atmosphere and loss processes, and are generally in line with other studies and assessments carried out in the Baltic Sea, e.g. Lundberg et al. 2009. Nutrient concentrations can be influenced also by upward mixing from deeper water layers (Vahtera et al. 2007; Feistel et al. 2008; Reissmann et al. 2009). Upwelling is an important source of phosphorus in the Gulf of Finland, the Gulf of Riga and also in the Baltic Proper (Nausch et al. 2009). The relatively high EQR values found in the south-eastern Baltic Proper (0.75), the western Gotland Basin (0.81), and the south-eastern Kattegat (0.78) are assumed to be related to imprecise setting of RefCon. There is a need for the development of more harmonised information on RefCon values for nutrient concentrations.

Phytoplankton is perhaps the most important element in any assessment of eutrophication in the Baltic Sea, since phytoplankton primary production and biomass are essentially coupled to nutrient concentrations. Chlorophyll-a concentrations are widely used as a proxy for phytoplankton biomass, 
but other indicators should be developed, e.g. in regard to algal species indicative of nuisance or toxic algal blooms. The findings presented here are generally in line with other studies and assessments, e.g. Jaanus et al. (2007), Fleming-Lehtinen et al. (2008), Håkansson and Lindgren (2008), Wasmund and Siegel (2008). During recent decades, chlorophyll-a concentrations have been increasing in most of the Baltic Sea sub-regions, although in the 2000s chlorophyll-a levels in many open sea areas show signs of a decreasing trend. RefCon values for chlorophyll-a in open waters seem appropriate for the time being. For coastal waters there seem to be a need for joint principles and methods of setting not only RefCon values, but also AcDev's. This has not yet been achieved by the WFD intercalibration activity.

The assessment of water transparency is closely linked to the assessment of phytoplankton and SAV, and in this study water transparency is regarded as a proxy of eutrophication. An added value in regard to water transparency is the length of the time series, which extends close to 100 years back in time (Sanden and Håkansson 1996). The findings presented here are generally in line with other studies and assessments, e.g. Kautsky et al. (1986), and Eriksson et al. (1998, 2002). In the Gulf of Riga, low status is consistent with lower RefCon compared to other areas. Low status in the Gulf of Bothnia may be attributed mostly to changes in land use affecting water colour (humic substances), whereas in the Gulf of Finland the increase of phytoplankton biomass is a more likely proximate reason for the low status.

The benthic invertebrate assessment for open waters shows that the benthic communities are structured by a combination of physical factors (e.g. salinity and sediment type) and eutrophication, which result in a higher susceptibility to hypoxia/anoxia. The findings presented here are generally in line with other studies and assessments, e.g. Karlson et al. (2002), and Perus and Bonsdorff (2004). A special challenge is the difficulty in defining historical RefCon for macrozoobenthos-this emphasizes the importance of conducting long-term monitoring over large spatial scales to be able to assess changes.

Assessment of SAV in coastal waters is, at least compared to the assessment of open waters, somewhat more challenging because the status of SAV communities depends on a variety of local environmental conditions which also affect also the eutrophication processes on very limited, local scale, e.g. changes in nutrient loading to specific river basin or fjord or bay while open sea indicators reflect situation on larger sea area. So it is no surprise that especially in case of extensive archipelago areas some SAV indicators can show development in opposite direction than indicators of nearby open sea areas. In our case some recovery in the depth distribution of SAV has occurred during last decades in the Northern Baltic Proper (extensive archipelago areas) as well as in some areas of the Gulf of Finland, while indicators used for open sea areas still show declining status.

There is in our opinion no such thing as a perfect assessment tool. More targeted monitoring and improved understanding of the eutrophication processes will lead to better knowledge, better indicators and subsequently better assessment tool. The strength of HEAT compared to the OSPAR equivalent on which it is built, is that it is modernized in the sense it makes use of (1) the EQR and the 'one out, all out' principle. Hence, HEAT is directly linked to the principles for assessment of ecological status of coastal water sensu the WFD. An added value of HEAT is that it enables a secondary assessment of confidence (see Andersen et al. 2010). Compared to OSPAR COMP, the HEAT tool has no or few weaknesses. When using HEAT for assessment of 'ecological status' sensu the WFD, it can be argued that 'eutrophication status' and 'ecological status' are different issues. This point is for somewhat meaningless, at least for the Baltic Sea, where the major threat to the coastal ecosystems is nutrient enrichment and eutrophication. It can also be argued the combination of indicators per QE mixes indicators with different boundary setting, but here it should be eminent that the classes used by the WFD are related to $\mathrm{QE}$ (cf. Annex 5), not to individual indicators or indices.

By providing a regional overview of eutrophication status in the Baltic Sea the results of this study provide interesting perspectives and links to the implementation of a range of EU Directives, e.g. the WFD, the MSFD (Anon. 2008a), the EC Urban Wastewater Treatment Directive (Anon. 1991a) and the EC Nitrates Directive (Anon. 1991b). The relations in regard to boundary setting and classification are discussed and outlined in Anon. (2009) and HELCOM (2009). If the convergence of the aims of 
these directives is taken seriously, marine waters classified as 'affected by eutrophication' could by no means be accepted as having either 'Good Ecological Status' or habitats with a 'Favourable Conservation Status'. Similarly it can be argued that waters classified as 'affected by eutrophication' should be designated as 'sensitive' to nutrient inputs from industries and cities. Along the same lines waters affected by eutrophication should be regarded as 'polluted' when situated downstream of catchment dominated by agriculture, implying that the catchment should be designated as 'vulnerable' in regard to losses of nitrogen from agricultural practices.

Future assessments will however be worthless if we fail to safeguard the current spatial and temporal resolution of HELCOM COMBINE and monitoring for the joint HELCOM core set of eutrophication indicators. Any weakening of these activities will jeopardize future re-assessments of eutrophication status of the Baltic Sea. Issues to be improved before a re-assessment include: (1) harmonization and evaluation of the quality of reference condition values (RefCon), (2) improvements of the target values (e.g. AcDev) (more research on functional relations, natural variations etc.), (3) improvements in spatial and temporal coverage of HELCOM COMBINE monitoring in some areas (e.g. Gulf of Riga, eastern Baltic Proper, South-eastern Baltic proper), (4) adequate monitoring of SAV, (5) development of oxygen indicators, and (6) development of statistical principles for weighting indicators.

The current impaired status of most parts of the Baltic Sea is a consequence of a combined increase in population density and altered agricultural practices. This has resulted in increased discharges, emissions (including atmospheric nitrogen emissions) and losses of nutrients to the environment and ultimately nutrient enrichment in the aquatic environment. Only few data series of nutrient loading exist, e.g. Stålnacke (1996) and Conley et al. (2007), and hence, the long-term nutrient enrichment will have to be documented by the temporal trends for $\mathrm{TN}$ and $\mathrm{TP}$ concentrations as well as TN:TP ratio in surface $(0-10 \mathrm{~m})$ and bottom waters $(>100 \mathrm{~m})$ starting from the 1970s until 2006 (HELCOM 2009).

Nutrient concentrations increased until the 1980s, and in all areas except for the Gulf of Finland, phosphorus concentrations have declined during the past two decades (HELCOM 2009). Nitrogen concentrations have declined in the Gulf of Riga, the Baltic Proper and the Danish Straits. These declines, particularly in the coastal zone, are partly caused by lower nutrient loads from land. Furthermore, changing volumes of hypoxia in the Baltic Proper significantly alter nutrient concentrations in bottom waters and, through subsequently mixing, also in surface waters. This does not affect the Baltic Proper alone but also connecting basins through advective exchanges. In particular, the Gulf of Finland has been severely affected by internal loading of phosphorus from the sediments caused by poor oxygen conditions (Vahtera et al. 2007).

The elevated nutrient concentrations compared to RefCon are primarily a consequence of a long-term $(100+$ years $)$ increase in direct and riverine loads to the Baltic Sea. However, management strategies focusing mainly on direct discharges have during the last 20 years resulted in a decrease in loads to the Baltic Sea (Fig. 7). However, it has to be taken into

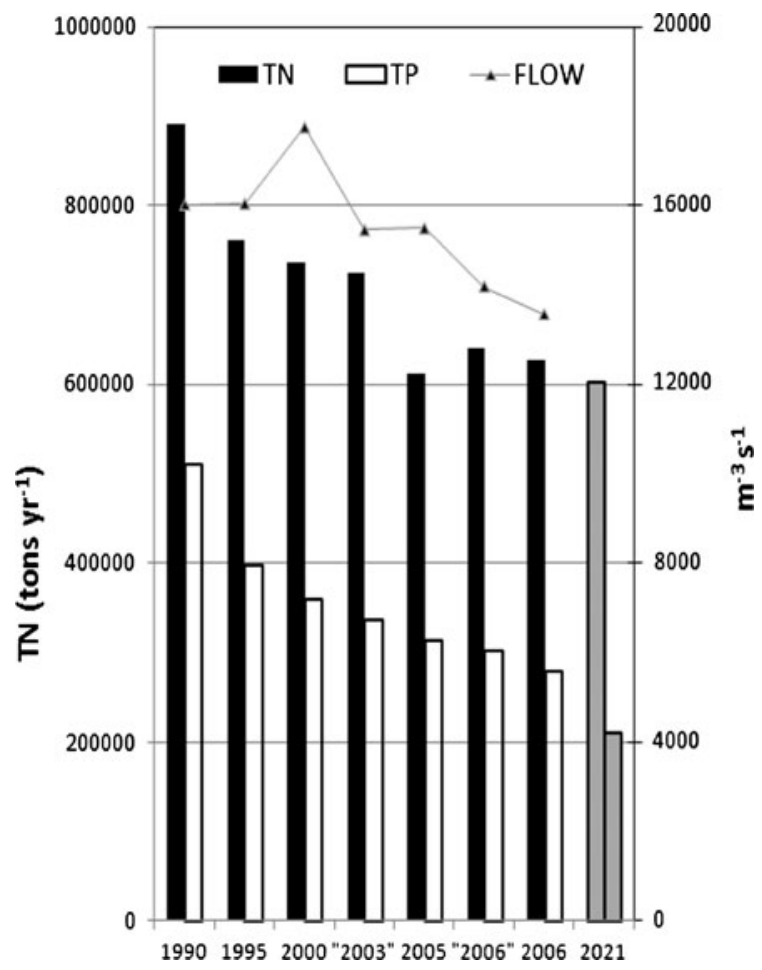

Fig. 7 Trends in inputs of total nitrogen (TN) and total phosphorus (TP) to the Baltic Sea. Please note that the TP input has been scaled by factor 10 . The solid line indicate run off in $\mathrm{m}^{3} \mathrm{~s}^{-1}$. "2003" = 2001-2003 and "2006" = 2001-2006. 2021 (grey bars) show the ultimate nutrient input targets to be reached as agreed by the HELCOM Baltic Sea Action Plan 
account that decreased flow is also partly responsible for decreasing loads (HELCOM 2009).

Improving the eutrophication status, especially of those areas classified as affected by eutrophication, relies on a better linking of ecosystem effects, nutrient concentrations, loads and human activities in upstream catchments. The key issue is to reverse the trend of eutrophication, sometimes referred to as oligotrophication (Nixon 2009), and to reduce inputs of nutrients to the Baltic Sea region. Some improvement has been made in some regions (Carstensen et al. 2006 and Fig. 7) but additional reductions are clearly needed. Recent modelling efforts (Wulff et al. 2007; Savchuk et al. 2008) have come a long way in providing advice on the magnitude of nutrient input reductions required to reach identified target levels of key parameters, such as those utilised in this study (Fig. 2). A first round of such calculations was actually adopted in 2007 by Baltic Sea states in the BSAP, partly based on an ecosystem approach to management of human activities (HELCOM 2007b; Wulff et al. 2007). Recently, a process of revision of these reduction figures was begun, taking into account more assessment parameters and atmospheric deposition to better reflect relevant ecosystem elements and all relevant pathways of nutrient input.

When developing and implementing ecosystembased nutrient management strategies, it has been debated whether a nutrient management strategy such as the BSAP should focus either on N, P or both (Tamminen and Andersen 2007). Given the variations in nutrient limitation between region and seasons - and the fact that the flow out of the Baltic Sea passes areas which are nitrogen limited-it is clear that alleviation of eutrophication requires a balanced and strategic approach to control both nitrogen and phosphorus appropriately (Conley et al. 2009b).

What we consider in our assessment of eutrophication or ecological status being a straightforward eutrophication signal is in reality a response not only to nutrient enrichment, but also to many other pressures (Jackson et al. 2001). Often the functional relations are complicated, including issues like thresholds, regime shifts and climate change (Duarte et al. 2009; Duarte 2009). The implications for management are currently being understood and interpreted. A rational solution would be to acknowledge that other pressures (e.g. climate change) might enhance eutrophication signals and that further efforts in regard to reduction of nutrient inputs may been needed to comply with most eutrophication related objectives.

\section{Conclusions}

This study has introduced a multi-metric indicatorbased eutrophication assessment tool enabling a harmonized assessment of eutrophication status in the whole Baltic Sea. Most parts of the Baltic Sea are, not surprisingly, judging from available scientific literature, affected by nutrient enrichment.

The recently developed HEAT as described in this paper provides a qualified answer to this key question "Do we have a problem or not?" and thus a basis for the implementation or revision of a Baltic Sea-wide nutrient management strategy, e.g. the BSAP.

HEAT represents a major step forward in terms of assessing eutrophication in the Baltic Sea. Firstly, because HEAT is based on well-established eutrophication indicators, it is in line with the principles of the WFD, and, perhaps more importantly, it uses the EQR approach to enable direct comparisons of all areas assessed despite variation in monitoring activities. Secondly, HEAT classifications can be regarded as a baseline for the reduction figures defined in the eutrophication segment of the BSAP against which the HELCOM vision of a Baltic Sea unaffected by eutrophication can be judged.

HEAT has shown itself to be a good tool and should be used for a HELCOM re-assessment of the eutrophication status of the Baltic Sea within e.g. 6-10 years in order to follow the implementation of the BSAP and validate the effectiveness of the reduction measures established so far.

Future assessments should be based on the best scientifically based indicators and assessment tools available rather than waiting for so-called 'perfection'. However, development of eutrophication assessment tools and nutrient management strategies in the Baltic and elsewhere should ideally be adaptive: there should always be the intention to adapt these tools when new scientific knowledge becomes available. Similarly, nutrient management strategies should be based on the best available science-based functional relations between causes and effects, using models and Decisions Support 
Systems as appropriate. Eutrophication in the Baltic Sea is a significant challenge and the absence of faultless tools should not prevent the Baltic Sea countries from trying to meet this challenge.

Acknowledgements The views expressed are those of the authors and do not necessarily represent official positions of their institutions. The authors would like to thank national and local authorities, and colleagues for making monitoring data available for the HELCOM integrated thematic assessment of eutrophication in the Baltic Sea region. Special thanks are owed to: Juris Aigars, Mats Blomqvist, Saara Bäck, Alf B. Josefson, Henning Karup, Pirkko Kauppila, Pirjo Kuuppo, Juha-Markku Leppänen, Bärbel Müller-Karulis, Samuli Neuvonen, Janet Pawlak, Heikki Pitkänen, Johnny Reker and Roger Sedin. This work has received financial support from HELCOM (HELCOM EUTRO and HELCOM EUTRO-PRO), the Danish Ministry for the Environment (CO-EUTRO) and DHI.

Open Access This article is distributed under the terms of the Creative Commons Attribution Noncommercial License which permits any noncommercial use, distribution, and reproduction in any medium, provided the original author(s) and source are credited.

\section{References}

Aarup T (2002) Transparency of the North Sea and Baltic Sea-a Secchi depth data mining study. Oceanologia 44:323-337

Ærtebjerg G, Andersen JH, Hansen OS (eds) (2003) Nutrients and eutrophication in Danish marine waters. A challenge for science and management. National Environmental Research Institute, Roskilde, p 126

Andersen JH, Murray C, Kaartokallio H, Axe P, Molvær J (2010) A simple method for confidence rating of eutrophication status classifications. Mar Pollut Bull. doi: 10.1016/j.marpolbul.2010.03.020

Anon. (1991a) Council Directive of 21 May 1991 concerning urban waste water treatment (91/271/EEC). Official Journal of the European Communities L 135

Anon. (1991b) Council Directive 91/676/EEC of 12 December 1991 concerning the protection of waters against pollution caused by nitrates from agricultural sources. Official Journal of the European Communities L 375

Anon. (2000) Directive 200/60/EC of the European Parliament and of the Council of 23 October2000 establishing a framework for Community action in the field of water policy. Official Journal of the European Communities L $327 / 1$

Anon. (2001) Land cover for Baltic Sea drainage basin region. http://www.grida.no/baltic/htmls/related1.htm. Accessed 19 May 2009

Anon. (2005) Common Implementation Strategy for the Water Framework Directive (2000/60/EC) Guidance Document No. 14. Guidance on the Intercalibration Process 2004-2006, 26 pp
Anon. (2008a) Directive 2008/56/EC of the European Parliament and of the Council of 17 June 2008 establishing a framework for community action in the field of marine environmental policy (Marine Strategy Framework Directive). Official Journal of the European Communities L $164 / 19$

Anon. (2008b) Commission decision of 30 October 2008 establishing, pursuant to Directive 2000/60/EC of the European Parliament and of the Council, the values of the Member State monitoring system classifications as a result of the intercalibration exercise. Official Journal of the European Union L 332/20

Anon. (2009) Guidance document on eutrophication assessment in the context of European water policies. Version 14, 17 May 2009, 140 pp

Backer H, Leppänen JM (2008) The HELCOM system of a vision, strategic goals and ecological objectives: implementing an ecosystem approach to the management of human activities in the Baltic Sea. Aquat Cons 18(3): 321-334

Bonsdorff E, Pearson TH (1999) Variation in the sublittoral macrozoobenthos of the Baltic Sea along environmental gradients: a functional group approach. Aust $\mathrm{J}$ Ecol 24:312-326

Borja A, Bald J, Franco J, Larreta J, Muxika I, Revilla M, Rodríguez JG, Solaun O, Uriarte A, Valencia V (2009) Using multiple ecosystem components, in assessing ecological status in Spanish (Basque Country) Atlantic marine waters. Mar Pollut Bull 59:54-64

Borum J (1996) Shallow waters and land/sea boundaries. In: Jørgensen BB, Richardson K (eds) Eutrophication in coastal marine ecosystems. Coastal and Estuarine Studies 52. American Geophysical Union, Washington, DC, p 272

Boström C, Baden SP, Krause-Jensen D (2003) The seagrasses of Scandinavia and the Baltic Sea. In: Green EP, Short FT (eds) World atlas of seagrasses. University of California Press, Berkeley, pp 27-37

Bricker SB, Ferreira JG, Simas T (2003) An integrated methodology for assessment of estuarine status. Ecol Modell 169:39-60

Bricker S, Longstaff B, Dennison W, Jones A, Boicourt K, Wicks C, Woerner J (2008) Effects of nutrient enrichment in the nation's estuaries: a decade of change. Harmful Algae 8:21-32

Carstensen J, Conley DJ, Andersen JH, Ærtebjerg G (2006) Coastal eutrophication and trend reversal: a Danish case study. Limnol Oceanogr 51(1,2):398-408

CIESN \& CIAT (2005) Center for International Earth Science Information Network (CIESIN), Columbia University; and Centro Internacional de Agricultura Tropical (CIAT). Gridded Population of the World Version 3 (GPWv3): Population Density Grids. Palisades, NY: Socioeconomic Data and Applications Center (SEDAC), Columbia University. http://sedac.ciesin.columbia.edu/gpw. Accessed 19 May 2009

Claussen U, Zevenboom W, Brockmann U, Topcu D, Bot P (2009) Assessment of the eutrophication status of transitional, coastal and marine waters within OSPAR. Hydrobiologia. doi:10.1007/s10750-009-9763-3

Cloern J (2001) Our evolving conceptual model of the coastal eutrophication problem. Mar Ecol Prog Ser 210:223-253 
Conley DJ, Carstensen J, Ærtebjerg G, Christensen PB, Dalsgaard T, Hansen JLS, Josefson AB (2007) Long-term changes and impacts of hypoxia in Danish coastal waters. Ecol Appl 17:165-184

Conley DJ, Björck S, Bonsdorff E, Carstensen J, Destouni G et al (2009a) Hypoxia-related processes in the Baltic Sea. Environ Sci Technol 43(10):3412-3420

Conley DJ, Paerl HW, Howarth RW, Boesch DF, Seitzinger SP, Havens KE, Lancelot C, Likens GE (2009b) Controlling eutrophication: nitrogen and phosphorus. Science 323:1014-1015

Duarte CM (2009) Coastal eutrophication research: a new awareness. Hydrobiologia. doi:10.1007/s10750-0099795-8

Duarte CM, Conley DJ, Carstensen J, Sánchez-Camacho M (2009) Return to neverland: shifting baselines affect eutrophication restoration targets. Estuar Coasts 32:29-36. doi:10.1007/s12237-008-9111-2

Eriksson BK, Johansson G, Snoeijs P (1998) Long-term changes in the sublittoral zonation of brown algae in the southern Bothnian Sea. Eur J Phycol 33:241-249

Eriksson BK, Johansson G, Snoeijs P (2002) Long-term changes in the macroalgal vegetation of the inner Gullmar Fjord Swedish Skagerrak coast. J Phycol 38:284-296

Feistel R, Nausch G, Wasmund N (eds) (2008) State and evolution of the Baltic Sea, 1952-2005. John Wiley \& Sons Inc, Hoboken, New Jersey, p 703

Fleming-Lehtinen V (ed) (2007) HELCOM EUTRO: development of tools for a thematic eutrophication assessment for two Baltic Sea sub-regions, The Gulf of Finland and The Bothnian Bay. MERI No. 61, Report Series of the Finnish Institute of Marine Research, 35 pp

Fleming-Lehtinen V, Laamanen M, Kuosa H, Haahti $H$, Olsonen R (2008) Long-term development of inorganic nutrients and chlorophyll $\mathrm{a}$ in the open Northern Baltic Sea. Ambio 37:86-92

Håkansson L, Lindgren D (2008) On regime shifts and budgets for nutrients in the open Baltic proper: evaluations based on extensive data between 1974 and 2005. J Coast Res 24:246-260

HELCOM (2002) Fourth Periodic Assessment of the State of the Marine Environment of the Baltic Sea, 1994-1998. Baltic Sea Environment Proceedings No. 82B. Helsinki Commission, 215 pp

HELCOM (2004) The Fourth Baltic Sea Pollution Load Compilation (PLC-4). Baltic Sea Environment Proceedings No. 93. Helsinki Commission, 188 pp

HELCOM (2006) Development of tools for assessment of eutrophication in the Baltic Sea. Baltic Sea Environmental Proceedings No. 104. Helsinki Commission, 64 pp

HELCOM (2007a) HELCOM Baltic Sea Action Plan. Helsinki Commission, $103 \mathrm{pp}$

HELCOM (2007b) Pearls of the Baltic Sea. In: Hegerhäll Aniasson B, Hägerhäll B (eds) Networking for life: special nature in a special sea. Helsinki Commission, 198 pp

HELCOM (2008) Manual for Marine Monitoring in the COMBINE Programme of HELCOM. http://www. helcom.fi/groups/monas/CombineManual/en_GB/main/. Accessed 4 June 2009

HELCOM (2009) Eutrophication in the Baltic Sea-an integrated thematic assessment of eutrophication in the Baltic
Sea region. Baltic Sea Environmental Proceedings No. 115B. Helsinki Commission, 148 pp

HELCOM (2010) Fifth Periodic Load Compilation. Helsinki Commission (in press)

Henriksen P (2009) Reference conditions for phytoplankton at Danish Water Framework Directive intercalibration sites. Hydrobiologia. doi:10.1007/s10750-009-9767-z

Jaanus A, Andersson A, Hajdu S, Huseby S, Jürgensone I, Olenina I, Wasmund N, Toming K (2007) Shifts in the Baltic Sea summer phytoplankton communities in 1992-2006. HELCOM Indicator Fact Sheets 2007. http://www.helcom.fi/environment2/ifs/en_GB/cover/

Jackson JBC, Kirby MX, Berger WH, Bjorndal KA, Botsford LW, Bourque BJ, Bradbury RH, Cooke R, Erlandson J, Estes JA, Hughes TP, Kidwell S, Lange CB, Lenihan HS, Pandolfi JM, Peterson CH, Steneck RS, Tegner MJ, Warner RR (2001) Historical overfishing and the recent collapse of coastal ecosystems. Science 293:629-638

Karlson K, Rosenberg R, Bonsdorff E (2002) Temporal and spatial large-scale effects of eutrophication and oxygen deficiency on benthic fauna in Scandinavian and Baltic waters-a review. Oceanogr Mar Biol 40:427-489

Kautsky N, Kautsky H, Kautsky U, Waern M (1986) Decreased depth penetration of Fucus vesiculosus (L.) since the 1940's indicates eutrophication of the Baltic Sea. Mar Ecol Prog Ser 28:1-8

Krause-Jensen D, Pedersen MF, Jensen C (2003) Regulation of eelgrass (Zostera marina) cover along depth gradients in Danish coastal waters. Estuaries 26:866-877

Leppäranta M, Myrberg K (2009) Physical oceanography of the Baltic Sea. Springer, Berlin, Heidelberg, p 410

Lundberg C, Jakobsson B-M, Bonsdorff E (2009) The spreading of eutrophication in the eastern coast of the Gulf of Bothnia, northern Baltic Sea-an analysis in time and space. Estuar Coast Shelf Sci 82:152-160

Lysiak-Pastuszak E, Krzyminski W, Lewandowski L (2009) Development of tools for ecological quality assessment in the Polish marine areas according to the Water Framework Directive. Part I-nutrients. Oceanol Hydrobiol Stud 38(3):87-99. doi:10.2478/v10009-009-0037-1

Martin G (1999) Distribution of phytobenthos biomass in the Gulf of Riga (1984-1991). Hydrobiologia 393:181-190

Nausch M, Nausch G, Lass HU, Mohrholz V, Nagel K, Siegel HM, Wasmund N (2009) Phosphorus input by upwelling in the eastern Gotland Basin (Baltic Sea) in summer and its effects on filamentous cyanobacteria. Estuar Coast Shelf Sci 83(4):434-442. doi:10.1016/j.ecss.2009.04.031

Nielsen SL, Sand-Jensen K, Borum J, Geertz-Hansen O (2002a) Depth colonisation of eelgrass (Zostera marina) and macroalgae as determined by water transparency in Danish coastal waters. Estuaries 25:1025-1032

Nielsen SL, Sand-Jensen K, Borum J, Geertz-Hansen O (2002b) Phytoplankton, nutrients and transparency in Danish coastal waters. Estuaries 25:930-937

Nilsson J, Engkvist R, Persson L-E (2004) Long-term decline and recent recovery of Fucus populations along rocky shores of southeast Sweden, Baltic Sea. Aquat Ecol 38: 587-598

Nixon SW (1995) Coastal marine eutrophication: a definition, social causes, and future concerns. Ophelia 41:199-219 
Nixon SW (2009) Eutrophication and the macroscope. Hydrobiologia. doi:10.1007/s10750-009-9759-z

NOAA (2007) Effects of nutrient enrichment in the nation's estuaries: a decade of change, national estuarine eutrophication assessment update. NOAA Coastal Ocean Program Decision Analysis Series No. 26. National Centers for Coastal Ocean Science, Silver Spring, MD, p 322

OSPAR (2003) OSPAR Integrated Report 2003 on the Eutrophication Status of the OSPAR Maritime Area Based Upon the First Application of the Comprehensive Procedure. Eutrophication Series. OSPAR Commission, 59 pp

OSPAR (2008) Second OSPAR Integrated Report on the Eutrophication Status of the OSPAR Maritime Area. Eutrophication Series. OSPAR Commission, $107 \mathrm{pp}$

Perus J, Bonsdorff E (2004) Long-term changes in macrozoobenthos in the Åland archipelago, northern Baltic Sea. J Sea Res 52:45-56

Pitkänen H, Lehtoranta J, Räike A (2001) Internal nutrient fluxes counteract decreases in external load: the case of the estuarial eastern Gulf of Finland, Baltic Sea. Ambio 30:195-201

Reinke J (1889) Algenflora des westlischen Ostsee Deutchen Antheils. Eine systematisch-pflanzengeographische Studie. Schmidt \& Klaunig, Kiel, p 101

Reissmann J, Burchard H, Feistel R, Hagen E, Lass HU, Mohrholz V, Nausch G, Umlauf L, Wieczorek U (2009) State of-the-art report on Baltic vertical mixing and consequences for eutrophication. Progr Oceanogr 82:47-80. doi:10.1016/1.pocean.2007.10.004

Rönnberg C, Bonsdorff E (2004) Baltic Sea eutrophication: area-specific ecological consequences. Hydrobiologia 514:227-241

Ryther JH, Dunstan WM (1971) Nitrogen, phosphorus, and eutrophication in the coastal marine environment. Science 171:1008-1013

Sandén P, Håkansson B (1996) Long term trends in Secchi depth in the Baltic Sea. Limnol Oceanogr 41(2):346-351

Savchuk OP, Wulff F, Hille S, Humborg C, Pollehne F (2008) The Baltic Sea a century ago-a reconstruction from model simulations, verified by observations. J Mar Sys 74(1-2):485-494

Schernewski G, Neumann T (2005) The trophic state of the Baltic Sea a century ago: a model simulation study. J Mar Sys 53(1-4):109-124
Stålnacke P (1996) Nutrient loads to the Baltic Sea. Linköping Studies in Art and Science No. 146, PhD Thesis. Linköping University

Svendsen LM, van der Bijl L, Boutrup S, Norup B (eds) (2005) NOVANA: Nationwide Monitoring and Assessment Programme for the Aquatic and Terrestrial Environments. Programme Description-Part 2. National Environmental Research Institute, Denmark. NERI Technical Report No. 537, $137 \mathrm{pp}$

Tamminen T, Andersen T (2007) Seasonal phytoplankton nutrient limitation patterns as revealed by bioassays over Baltic Sea gradients of salinity and eutrophication. Mar Ecol Prog Ser 340:121-138

Torn K, Krause-Jensen D, Martin G (2006) Present and past depth distribution of bladderwrack (Fucus vesiculosus) in the Baltic Sea. Aquat Bot 84:53-62

Vahtera E, Conley DJ, Gustafsson BG, Kuosa H, Pitkänen H, Savchuk OP, Tamminen $T$, Viitasalo M, Voss $M$, Wasmund N, Wulff F (2007) Internal ecosystem feedbacks enhance nitrogen-fixing cyanobacteria blooms and complicate management in the Baltic Sea. Ambio 36:186-194

von Wachenfeldt $T$ (1975) Marine benthic algae and the environment in the Öresund. I-III. PhD Thesis, Lund University

Waern M (1952) Rocky-shore algae in the Öregrund archipelago. Acta Phytogeogr Suec 30:1-298

Wasmund N, Siegel H (2008) Chapter 15. Phytoplankton. In: R Feistel, G Nausch, N Wasmund (eds) State and evolution of the Baltic Sea, 1952-2005. A detailed 50-year survey of meteorology and climate, physics, chemistry, biology, and marine environment. Wiley, pp 441-481

Wasmund N, Andrushaitis A, Lysiak-Pastuszak E, MüllerKarulis B, Nausch G, Neumann T, Ojaveer H, Olenina I, Postel L, Witek Z (2001) Trophic status of the southeastern Baltic Sea: a comparison of coastal and open areas. Estuar Coast Shelf Sci 53:849-864

Wulff F, Savchuk OP, Sokolov AV, Humborg C, Mörth M (2007) Management options and effects on a marine ecosystem: assessing the future of the Baltic Sea. Ambio 36:243-249 